\title{
Curso Superior de Tecnologia em Gestão de Turismo: empregabilidade, perspectivas e percepções do egresso do IFSP
}

\section{Tourism Management Foundation Degree Course: IFSP graduates' employability, perspectives and perceptions}

\section{Curso de Tecnicatura en Gestión del Turismo: empleabilidad, perspectivas y percepciones de los graduados de IFSP}

Glauber Eduardo de Oliveira Santos ${ }^{1}$

Brenno Vitorino Costa ${ }^{2}$

Rafaela Camara Malerba ${ }^{3}$

\begin{abstract}
Resumo
O surgimento dos cursos superiores de tecnologia em Gestão de Turismo alterou substancialmente o cenário da educação superior em Turismo no Brasil. Contudo, poucas informações a respeito da empregabilidade, perspectivas e percepções dos egressos desses cursos estão disponíveis. Com vistas a contribuir para o planejamento e orientação dos cursos de tecnologia em Turismo, este artigo apresenta os resultados de uma pesquisa realizada com os egressos do curso de Tecnologia em Gestão de Turismo do campus São Paulo do Instituto Federal de Educação, Ciência e Tecnologia de São Paulo (IFSP). A pesquisa coletou dados junto a 338 ex-alunos acerca de suas relações com o mercado de trabalho, sequência de estudos e percepções sobre o curso. Os resultados apresentados destacam que os egressos do IFSP têm alcançado altos níveis de empregabilidade. Dentre os principais motivos que afastam alguns deles da área profissional do turismo estão o fato de o indivíduo já estar estabelecido em outra área e a baixa remuneração. Nota-se também que a taxa de empregabilidade dos egressos tem aumentado ao longo do tempo, fato que pode estar associado não apenas ao aprimoramento do curso, como também ao processo de formação de reconhecimento do curso pelas empresas do mercado. As principais atividades empregadoras dos egressos são agenciamento de viagens, eventos, hotelaria e companhias aéreas. Os egressos que atuam profissionalmente na área de turismo se mostram relativamente satisfeitos com seus trabalhos.
\end{abstract}

Palavras-chave: Educação; Ensino superior; Tecnologia em Gestão de Turismo; Egressos; Mercado de trabalho.

\footnotetext{
${ }^{1}$ Bacharel e mestre em Turismo pela Escola de Comunicações e Artes da Universidade de São Paulo (ECA-USP) e doutor em Economia do Turismo e do Meio Ambiente pela Universidade das Ilhas Baleares (Espanha). Professor do Instituto Federal de Educação, Ciência e Tecnologia de São Paulo (IFSP). E-mail: glaubereduardo@gmail.com

${ }^{2}$ Bacharel em Turismo pela ECA-USP, especialista em Ecoturismo pelo SENAC-SP e mestre em Hospitalidade pela Universidade Anhembi Morumbi. Coordenador e professor do curso de Tecnologia em Gestão de Turismo do Instituto Federal de Educação, Ciência e Tecnologia de São Paulo (IFSP). E-mail:brenno.ifsp@ gmail.com

${ }^{3}$ Licenciada em Letras pela PUC/SP. Bacharel em Turismo e especialista em Gestão Mercadológica de Turismo e Hotelaria pela ECA-USP. Mestre em Hospitalidade pela Universidade Anhembi Morumbi. Professora do Instituto Federal de Educação, Ciência e Tecnologia de São Paulo (IFSP). E-mail: rafaelamalerba@gmail.com
} 


\begin{abstract}
The emergence of foundation degree courses in Tourism Management has deeply changed Tourism Higher Education scene in Brazil. However, there are little information about graduates' employability, perspectives and perceptions. In order to contribute to Tourism foundation courses' planning, this paper presents the results of a survey carried out with 338 graduates from the Tourism Management Course of the Federal Institute of Education, Science and Technology of São Paulo - IFSP. The study collected data on their relationships with labor market, further studies and perceptions on the course. Results show that IFSP graduates have achieved high levels of employability, especially in tour operators, travel agencies, hotels, events and airline companies. Low wages offered by tourism industry and the fact of being already established in another sector are the main reasons that keep some graduates away from tourism jobs. On the other hand, the study reveals an increasing employment rate, which could be related not only to course improvements, but also to the increasing recognition of the course by tourism companies. In general, those graduates that work in the Tourism sector are satisfied with their jobs.
\end{abstract}

Keywords: Education; Higher Education; Tourism Managment Foundation Degree; Graduates; Labor market.

\title{
Resumen
}

El surgimiento de Cursos de Tecnicatura en Gestión del Turismo ha alterado sustancialmente el panorama de la educación superior en Turismo en Brasil. Sin embargo, hay poca información acerca de las perspectivas, la empleabilidad y las percepciones de los graduados. Así, para contribuir a la planificación y orientación de cursos de Tecnicatura en Turismo, este artículo presenta los resultados de una encuesta de seguimiento a graduados del curso de Tecnicatura en Gestión del Turismo del Instituto Federal de Educação, Ciência e Tecnologia de São Paulo - IFSP. La encuesta recogió datos de 338 graduados acerca de sus relaciones con el mercado de trabajo, nuevos estudios y reflexiones sobre el curso. Los resultados indican que los egresados del IFSP han alcanzado altos niveles de empleabilidad. Las principales razones que mantienen algunos graduados fuera del sector turístico profesional son los bajos salarios ofrecidos y el hecho de que esté establecido en otro sector. Los resultados señalan también que la tasa de empleo de los graduados ha aumentado con el tiempo, o que puede estar asociado no sólo a la mejora del curso, pero también con el proceso de reconocimiento de la formación por las empresas del mercado turístico. Las principales actividades donde trabajan los egresados son agencias y operadores de viajes, eventos, hoteles y líneas aéreas. Los graduados que trabajan profesionalmente en el turismo están relativamente satisfechos con su trabajo.

Palabras clave: Educación; Educación Superior; Tecnicatura en Gestión del Turismo; Graduados; Mercado de Trabajo. 


\section{Introdução}

Os cursos superiores de Turismo no Brasil cresceram substancialmente nos anos 1990. Já nos anos 2000 a procura por esses cursos caiu, ocasionando uma readequação da oferta que envolveu a redução do número total de cursos e vagas e o surgimento dos cursos superiores de tecnologia. Em 2014 havia 108 cursos de Tecnologia em Gestão de Turismo no país (BRASIL, 2014). Contudo, poucas informações a respeito dos resultados desses cursos estão disponíveis para dar suporte ao planejamento e administração dos mesmos, especialmente no que diz respeito à empregabilidade, perspectivas e percepções do egresso.

Com vistas a contribuir para análises mais sólidas e consistentes acerca dos cursos de tecnologia em Turismo, este artigo apresenta os resultados de uma pesquisa realizada com os egressos do curso de tecnologia em Gestão de Turismo do campus São Paulo do Instituto Federal de Educação, Ciência e Tecnologia de São Paulo - IFSP. A pesquisa coletou dados junto a 338 ex-alunos acerca de suas relações com o mercado de trabalho, sequência de estudos e percepções sobre o curso. Os resultados desta pesquisa são apresentados e analisados neste artigo após uma breve contextualização dos cursos superiores de Turismo no Brasil, com especial atenção aos cursos de tecnologia e ao curso do IFSP.

\section{Evolução do Ensino Superior em Turismo no Brasil}

O turismo ganhou espaço no ensino superior a partir da década de 1960 na Europa e nos Estados Unidos, quando surgiram cursos para atender às demandas do que parecia ser um promissor setor econômico (AIREY, 2008b; REJOWSKI, 1996). Até as décadas de 1970 e 1980, os cursos de Turismo emergiam de diferentes departamentos relacionados à geografia, negócios ou esportes, e priorizavam o treinamento de habilidades para trabalho no setor turístico, a ampliação dos estudos de administração ou o desdobramento de disciplinas tradicionais (COOPER, SHEPERD, WESTLAKE, 2001).

A partir de 1990, entretanto, ocorreram duas mudanças significativas no desenvolvimento da educação em turismo. Primeiramente, o currículo se expandiu além de suas origens profissionalizantes e passou a abordar temas mais abrangentes como a antropologia, o meio ambiente, entre outros. Consequentemente e em razão também do crescimento contínuo da atividade turística, os programas da área passaram a atrair estudiosos e pesquisadores de 
outras disciplinas (AIREY, 2008a). Assim, o turismo deixou de ser apenas um pequeno campo de estudo suplementar de disciplinas mais reconhecidas para constituir uma área abrangente, complexa, com infraestrutura educacional e intelectual, lastro curricular, comunidade acadêmica e bibliografia própria (AIREY, 2008b; COOPER, SHEPERD, WESTLAKE, 2001).

No Brasil, a educação superior em turismo iniciou-se na década de 1970 com a abertura de dezesseis cursos de Turismo em diferentes instituições, especialmente na região Sudeste (TEIXEIRA, 2006). O primeiro curso iniciou-se em São Paulo, no ano de 1971, na Faculdade de Turismo do Morumbi, atual Universidade Anhembi Morumbi. A ele, em 1973, seguiu-se o curso da Escola de Comunicações e Artes da Universidade São Paulo - ECA/USP - que, conforme Teixeira (2006), possibilitou o fortalecimento do turismo como objeto de estudo acadêmico e científico, por ser o primeiro bacharelado em Turismo oferecido por instituição pública. Cabe destacar que, ao contrário do que ocorreu na Europa ocidental e na América do Norte, muitos dos cursos do Brasil iniciaram-se com autonomia própria, por iniciativa de seus fundadores (BARRETTO, TAMANINI, SILVA, 2004).

O surgimento da educação superior em Turismo na década de 1970 pode ser explicado por três principais fatores: o amadurecimento profissional do setor, a valorização do lazer e a falta de vagas em instituições de ensino superior, que estimulava a abertura de novos cursos, notadamente em instituições privadas (TEIXEIRA, 2006). Além disso, pode-se dizer que o surgimento dos cursos de Turismo estava relacionado ao projeto desenvolvimentista nacional, em que se destaca se a criação do Conselho Nacional de Turismo - CNTur - e da Empresa Brasileira de Turismo - EMBRATUR - no ano de 1966, tendo como principais ações a ampliação do parque hoteleiro nacional e a fiscalização das atividades das agências de viagens (DENCKER, 2006; REJOWSKI, 1996; TEIXEIRA, 2006).

Na década de 1980, novos cursos foram criados, mas muitos se encerraram brevemente, devido aos impactos da crise econômica que atingia o país no momento (ANSARAH, 2002). Dessa forma, até 1996, o crescimento da oferta de cursos de Turismo foi moderado, somando 40 cursos superiores de Turismo, 8 de Hotelaria; 1 de Turismo e hotelaria. A ampla maioria desses cursos $(83 \%)$ era oferecida por instituições privadas, com destaque para as regiões Sudeste e Nordeste (ANSARAH, REJOWSKI, 1996). Em seis anos, este número cresceu em proporções gigantescas, atingindo em 2002 um total 293 bacharelados em Turismo, 22 em 
Hotelaria e 19 em Turismo e Hotelaria, ainda com predomínio das instituições privadas (ANSARAH, 2002). A procura por formação em turismo também cresceu. No vestibular da USP para 1997, por exemplo, havia 73,6 inscritos por vaga, mais que o dobro dos inscritos para carreiras tradicionais como medicina, direito e engenharia (FUVEST, 1996). Entretanto, a partir de meados dos anos 2000, observou-se uma diminuição na procura por vagas em cursos de Turismo, ocasionando uma readequação da oferta: instituições públicas passam a ofertar bacharelados em Turismo, e instituições privadas os substituíram por cursos superiores de tecnologia.

Diante deste quadro, na década seguinte, notou-se o surgimento da preocupação da academia com a qualidade dos cursos da área de turismo que contavam com uma oferta muito ampla de vagas, muitas das quais não preenchidas (ANSARAH, 2002; CARVALHO, 2008). Além disso, nos anos 2000, observou-se a expansão da oferta dos cursos superiores de Tecnologia na área de Hospitalidade e Lazer: Eventos, Gastronomia, Gestão Desportiva e de Lazer, Gestão de Turismo e Hotelaria.

\section{Dimensão da Oferta de Cursos Superiores na Área de Turismo no Brasil}

Em maio de 2014, o Ministério da Educação (BRASIL, 2014) contabilizava 373 bacharelados presenciais em Turismo em atividade em todo o Brasil, incluindo cursos autorizados, mas que não necessariamente oferecem novas turmas. Dos 373, 355 são estritamente Bacharelados em Turismo e 13 apresentam habilitações variadas, como Lazer e Turismo, Turismo Binacional, entre outros. Desses 373 cursos, 323 (86,6\%) são oferecidos por instituições privadas, e os demais 55 por instituições públicas. No que diz respeito à localização dos mesmos, destaca-se a região Sudeste com 156 (41,8\%) deles; seguida pelo Nordeste, com 98 (26,3\%), e pelo Sul com $55(14,7 \%)$. As regiões Centro-Oeste e Norte oferecem apenas, respectivamente, 38 $(10,2 \%)$ e $26(7 \%)$ bacharelados presenciais em Turismo.

Em relação a bacharelados à distância, contabilizavam-se três em instituições privadas: Universidade do Sul de Santa Catarina - Unisul; Universidade Católica de Brasília - UCB, e Faculdade de Estudos Administrativos de Minas Gerais - FEAD-MG. Cabe destacar também duas licenciaturas em Turismo à distância, oferecidas pela Universidade Federal Rural do Rio de Janeiro (UFFRJ) e pela Universidade Federal do Estado do Rio de Janeiro - Unirio - e um 
curso sequencial presencial em Gestão de Negócios em Turismo, oferecido pelas Faculdades Integradas Olga Mettig - Famettig, de Salvador, Bahia.

No que tange ao ensino superior tecnológico, à mesma época, contabilizavam-se 439 cursos (presenciais ou à distância) na área de Lazer e Hospitalidade, sendo 141 (32,1\%) em Gastronomia, dos quais um à distância; 86 (19,5\%) em Eventos, 3 à distância; 73 (16,6\%) em Hotelaria; 4 deles à distância; 31 (7,0\%) em Gestão Desportiva e de Lazer, e, finalmente, 108 $(24,6 \%)$ em Gestão de Turismo. Dessas tecnologias, apenas 13,6\% são oferecidas por instituições públicas: 8 em Eventos, todas presenciais; 11 presenciais em Gastronomia; 12 em Hotelaria, 2 deles à distância; 2 presenciais em Gestão Desportiva e de Lazer e, finalmente, 27 em Gestão de Turismo, um deles à distância.

Em relação, especificamente, às Tecnologias em Gestão de Turismo, são oferecidos cursos principalmente nas regiões Sudeste $(41,7 \%)$ e Nordeste (30,6\%). A Observa-se o predomínio da oferta em instituições privadas $(75 \%)$ e a pouca expressividade dos cursos à distância, que totalizam $7,3 \%$ e são oferecidos majoritariamente por instituições privadas. O estado de São Paulo se destaca como o estado com maior oferta de cursos de Tecnologia em Gestão do Turismo: são 24 cursos, o que corresponde a 22,2\% da oferta nacional. Desses, 20 encontramse em instituições privadas e quatro em públicas, especificamente a Fatec/SP e o IFSP, sendo que este último tem cursos em atividade nos campi São Paulo, Barretos e Cubatão.

Tabela 1 detalha os números do ensino superior Tecnológico em Gestão de Turismo no Brasil, em relação à modalidade, tipo de instituição e região.

Observa-se o predomínio da oferta em instituições privadas $(75 \%)$ e a pouca expressividade dos cursos à distância, que totalizam 7,3\% e são oferecidos majoritariamente por instituições privadas. O estado de São Paulo se destaca como o estado com maior oferta de cursos de Tecnologia em Gestão do Turismo: são 24 cursos, o que corresponde a 22,2\% da oferta nacional. Desses, 20 encontram-se em instituições privadas e quatro em públicas, especificamente a Fatec/SP e o IFSP, sendo que este último tem cursos em atividade nos campi São Paulo, Barretos e Cubatão.

Tabela 1: Tecnologias em Gestão de Turismo No Brasil

\begin{tabular}{lcccccc} 
& \multicolumn{2}{c}{ À distância } & \multicolumn{2}{c}{ Presencial } & \\
Região & IES privada & IES pública & IES privada & IES pública & Total \\
\hline Centro-Oeste & 0 & 0 & 4 & 0 & 4 & $3,7 \%$ \\
\hline
\end{tabular}




\begin{tabular}{lcccccc}
\hline Nordeste & 2 & 0 & 25 & 6 & 33 & $30,6 \%$ \\
\hline Norte & 5 & 0 & 3 & 5 & 13 & $12,0 \%$ \\
\hline Sudeste & 1 & 1 & 34 & 9 & 45 & $41,7 \%$ \\
\hline Sul & 0 & 0 & 7 & 6 & 13 & $12,0 \%$ \\
\hline \multirow{2}{*}{ Total } & 8 & 1 & 73 & 26 & 108 & \multirow{2}{*}{$100 \%$} \\
\hline
\end{tabular}

Fonte: cálculos a partir de dados do E-MEC (BRASIL. MINISTÉRIO DA EDUCAÇÃO, 2014)

\section{Os Cursos Superiores de Tecnologia no Brasil}

A constituição dos cursos superiores de tecnologia no Brasil é resultante de um longo processo de implantação da educação profissional no país. Nos anos 1800 , há uma série de registros do ensino dos ofícios manufatureiros às camadas menos privilegiadas da sociedade. Crianças e jovens aprendiam ofícios como alfaiataria, carpintaria e tipografia, dentre outros, além da educação primária (BRASIL, 2009).

Apenas em 1909, por decreto do então presidente Nilo Peçanha, criaram-se as primeiras estruturas formais em nível federal de ensino técnico: as "Escolas de Aprendizes Artífices", somando 19 unidades espalhadas pelo Brasil, uma delas na cidade de São Paulo. Nas décadas seguintes, em razão da expansão industrial do país, muitas dessas escolas, nesta ou em outras denominações, foram criadas (BRASIL, 2009).

Em 1959 as escolas industriais e técnicas foram transformadas em Escolas Técnicas Federais, autarquias com autonomia didática e de gestão. Nesse momento, os egressos dos cursos ministrados por essas instituições já tinham ensino equivalente ao de ensino médio e poderiam ingressar no ensino superior (BRASIL, 2009).

Anos depois, o Decreto Federal 74.708, de 1974, reconheceu os cursos superiores de tecnologia oferecidos pela Faculdade de Tecnologia de São Paulo - FATEC-SP. Como consequência desse Decreto, em 1978, as Escolas Técnicas Federais do Paraná, de Minas Gerais e do Rio de Janeiro foram transformadas em Centros Federais de Educação Tecnológica - CEFET, com a atribuição complementar de formar tecnólogos e engenheiros de operação. Tal medida se estendeu às demais escolas da rede anos depois, particularmente a partir de 1994, com a instituição do Sistema Federal de Educação Tecnológica (BRASIL, 2009). A Escola Técnica Federal de São Paulo foi transformada em CEFET-SP em janeiro de 1999.

Paulatinamente, a educação profissional e tecnológica foi sendo reconhecida - especialmente pelo Governo Federal - como elemento estratégico para o desenvolvimento nacional. Como 
repercussão desta visão, em 2005 e 2007, a Rede Federal de Educação Profissional e Tecnológica ganhou dois Planos de Expansão, que juntos previam a implantação de 354 escolas até o final de 2010 (BRASIL, 2009). Além disso, concebeu-se um novo modelo de unidade de ensino, o Instituto Federal de Educação, Ciência e Tecnologia de São Paulo - IFSP, denominação que passou a servir à maioria dos CEFETs pelo Brasil, entre eles o CEFET-SP.

Quanto aos cursos de tecnologia, criados nos anos 1970 como mencionado anteriormente, no ano de 2002 uma Resolução do Conselho Nacional de Educação "institui as Diretrizes Curriculares Nacionais Gerais para a organização e o funcionamento dos cursos superiores de tecnologia" (Resolução CNE/CP 3, de 18 de dezembro de 2002). O Artigo $2^{\circ}$ da Resolução discorre sobre as finalidades desses cursos:

Art. $2^{\circ}$ Os cursos de educação profissional de nível tecnológico serão designados como cursos superiores de tecnologia e deverão:

I - incentivar o desenvolvimento da capacidade empreendedora e da compreensão do processo tecnológico, em suas causas e efeitos;

II - incentivar a produção e a inovação científico-tecnológica, e suas respectivas aplicações no mundo do trabalho;

III - desenvolver competências profissionais tecnológicas, gerais e específicas, para a gestão de processos e a produção de bens e serviços;

IV - propiciar a compreensão e a avaliação dos impactos sociais, econômicos e ambientais resultantes da produção, gestão e incorporação de novas tecnologias;

$\mathrm{V}$ - promover a capacidade de continuar aprendendo e de acompanhar as mudanças nas condições de trabalho, bem como propiciar o prosseguimento de estudos em cursos de pós-graduação;

VI - adotar a flexibilidade, a interdisciplinaridade, a contextualização e a atualização permanente dos cursos e seus currículos;

VII - garantir a identidade do perfil profissional de conclusão de curso e da respectiva organização curricular.

Em 2006 foi lançado o Catálogo Nacional dos Cursos Superiores de Tecnologia "para disciplinar as denominações dos cursos oferecidos por instituições de ensino público e privado" (BRASIL, 2009), sendo atualizado em 2010. No ano seguinte, foi a vez do Catálogo Nacional dos Cursos Técnicos.

\section{O Ensino Tecnológico de Turismo}

A criação de cursos profissionalizantes no âmbito do Turismo e áreas relacionadas teve como marco inicial a abertura do Curso Superior de Tecnologia em Hotelaria, ofertado pelo Serviço 
Nacional de Aprendizagem Comercial de São Paulo - SENAC-SP - no município de São Paulo e no Hotel-Escola de Águas de São Pedro, autorizado pelo Decreto Federal 97.333, de 1988.

Atualmente, o Catálogo Nacional de Cursos Superiores de Tecnologia, no eixo Hospitalidade e Lazer, lista cinco cursos superiores de tecnologia: Eventos, Gastronomia, Gestão Desportiva e de Lazer, Gestão de Turismo e Hotelaria.

Detalhes como a carga horária mínima, o escopo de cada curso e as possibilidades de atuação profissional do egresso estão dispostas no Catálogo. Essa publicação assim apresenta o tecnólogo em Gestão de Turismo:

O tecnólogo em Gestão de Turismo atua no planejamento e desenvolvimento da atividade turística nos segmentos público e privado. Desenvolve ações no âmbito do planejamento turístico, agenciamento de viagens (emissivas, receptivas e operadores de turismo), transportadoras turísticas e consultorias voltadas para o gerenciamento das políticas públicas e para a comercialização e promoção dos serviços relativos à atividade. A identificação dos potenciais turísticos do receptivo, considerando a diversidade cultural e os aspectos socioambientais para o desenvolvimento local e regional, constitui-se atividade relevante deste profissional. (BRASIL, 2010)

Embora a descrição seja relativamente genérica, nota-se um enfoque predominantemente profissional no qual a atuação do formado nas empresas do setor turístico é uma de suas grandes possibilidades.

\section{O Curso de Tecnologia em Gestão de Turismo do IFSP}

Logo após a transformação da Escola Técnica Federal de São Paulo em CEFET-SP, houve uma mudança no perfil dos cursos oferecidos, que não se tratava apenas de incluir os cursos superiores de tecnologia: os cursos técnicos integrados ao ensino médio deixaram de existir e a escola passou a oferecer o ensino médio comum, sem as disciplinas de formação profissionalizante. $\mathrm{O}$ número de vagas oferecidas para o ensino médio, então, caiu drasticamente, fazendo com que os professores do chamado "núcleo comum" (disciplinas de formação básica, como História, Geografia, Línguas, Biologia e Física, dentre outros) passassem a ter uma carga horária ociosa muito grande.

Ciente e preocupada com este fato, a direção do CEFET-SP convidou os professores do núcleo comum a montarem propostas de cursos superiores "de mercado", "atuais", nas 
palavras daquela direção. Da união de esforços de professores ligados às áreas acadêmicas de Códigos e Linguagens e de Sociedade e Cultura surgiu, finalmente, a proposta do curso de Tecnologia em Turismo e Hospitalidade, entregue à direção em meados de 2000. O curso proposto foi aprovado internamente e sua primeira turma ingressou em fevereiro de 2001.

A primeira organização curricular do curso foi um reflexo evidente do seu processo de formação: muitas disciplinas e uma grande carga horária dedicada às humanidades e pouco específica do Turismo. Em termos de enfoque, pode-se dizer que se tratava de um curso mais próximo aos bacharelados existentes do que a um curso de tecnologia. A semelhança com os bacharelados também se apresentava em sua extensa carga horária, com 2.965 horas.

O curso passou pelo processo de reconhecimento pelo Ministério da Educação em 2004 (Portaria 2.963 de 22 de Agosto de 2004), e a comissão externa de avaliação solicitou uma série de alterações que acabaram por modificar sua estrutura curricular, e inclusive seu nome. Dessa forma, no primeiro semestre de 2005, o CEFET-SP passou a oferecer o curso de Tecnologia em Turismo Receptivo. Nessa segunda organização, houve uma considerável redução do número de disciplinas de humanidades, diminuição do número de semestres de seis para cinco e uma queda na carga horária total (para 2.396 horas). Em contrapartida, houve um considerável incremento da carga horária dedicada à formação específica em Turismo. Tais alterações conferiram ao curso características mais evidentes de um curso de tecnologia. Além disso, o número de professores formados em Turismo foi progredindo ao longo dos anos, facilitando e contribuindo para as mudanças que aconteceram e que eram, de fato, necessárias.

Com a publicação do Catálogo Nacional de Cursos Superiores, em 2006, foi necessário passar por uma nova transição para atender aos termos do mesmo. Nesse sentido, o curso de Tecnologia em Turismo Receptivo manteve a estrutura curricular anterior, mas passou a se chamar Tecnologia em Gestão de Turismo, denominação que mantém até os dias atuais.

Em 2009, os alunos de todos os cursos de Tecnologia em Gestão de Turismo do Brasil foram convocados, pela primeira e única vez até o momento, a prestar o Exame Nacional de Desempenho de Estudantes - Enade. Neste certame, o curso do IFSP obteve a maior nota do país na categoria, e a terceira maior quando considerados também os cursos de bacharelado em Turismo (INSTITUTO NACIONAL DE ESTUDOS E PESQUISAS EDUCACIONAIS ANÍSIO TEIXEIRA, 2011). 
Ao longo de 2010, elaborou-se um novo Projeto Pedagógico de Curso, tendo em vista atender novas demandas econômicas e sociais e das transformações, especialmente no que diz respeito à gestão e à comercialização do turismo. Dessa forma, uma terceira estrutura curricular do Curso foi implementada a partir de fevereiro de 2011. O nome do curso não foi alterado, mas houve mais uma aproximação das disciplinas e seus conteúdos aos termos gestão e tecnologia que estão nele presentes. Novamente a carga horária total foi reduzida (2.037 horas) e o curso voltou a ser oferecido em seis semestres, de modo a tornar-se menos cansativo para os alunos, já que houve uma diminuição do número de disciplinas por semestre. Assim como no projeto anterior, projetos interdisciplinares e viagens técnicas continuaram tendo destaque, sendo considerados imprescindíveis para a formação do aluno.

Desde o início do curso, em 2001, são abertas 80 vagas por semestre, 40 no período matutino, 40 no noturno, à exceção de dois semestres nos quais foram oferecidas apenas as 40 vagas do período noturno. O número efetivo de alunos ingressantes não é exatamente este em todos os semestres, pois em alguns mais alunos foram chamados para compensar os que desistem com poucas semanas de aulas, e em outros simplesmente não houve candidatos aprovados no sistema de ingresso em número suficiente para completar as turmas. A Tabela 2 apresenta os números de alunos ingressos e egressos desde o início do curso.

Tabela 2: Quantidade de alunos formados em Gestão de Turismo no IFSP

\begin{tabular}{lccc}
\hline Grade & Ingressantes & Formados $^{4}$ & Taxa de concluintes \\
\hline Turismo e Hospitalidade (2001 a 2004) & $640^{5}$ & 322 & $50,31 \%$ \\
\hline Gestão de Turismo (2005 a 2010) & 874 & $322^{6}$ & $36,84 \%$ \\
\hline Total & 1514 & 644 & $42,54 \%$ \\
\hline
\end{tabular}

\section{Estudos com Egressos}

Segundo Airey (2008a), na atualidade, a educação em turismo enfrenta dois principais riscos: o de restringir-se a práticas profissionalizantes e reflexões sobre o mundo do trabalho e o de ignorar suas conexões com o setor turístico. A despeito de sua origem empresarial, observa-se no ensino superior em turismo uma distância da realidade empresarial (COOPER, SHEPERD,

\footnotetext{
${ }^{4}$ Por formado, entenda-se aquele que colou grau até dezembro de 2013.

${ }^{5}$ Este número é estimado. Não foi possível levantar o número de matrículas efetivamente realizadas

${ }^{6}$ Embora o ingresso de alunos nesta grade tenha se encerrado em 2010, ainda há, no momento da confecção deste artigo, um bom número de alunos cursando disciplinas equivalentes na grade nova ou que estão pendentes com componentes como o estágio curricular ou o Trabalho de Conclusão de Curso.
} 
WESTLAKE, 2001; WANG, AYRES, HUYTON, 2012), o que poderia ocasionar dificuldades para inserção dos egressos do mercado de trabalho. Para Stergious (2008), dois grandes dualismos envolvem essa discussão: o da teoria versus prática e o da abordagem profissionalizante ou empresarial versus perspectivas mais amplas. Segundo este autor, porém, educação superior em turismo deve ultrapassar essas dicotomias e realizar uma síntese entre a relevância profissionalizante e a educação desafiadora.

Uma ferramenta possível para a realização desta síntese corresponde à realização de estudos com egressos da educação superior, tendo em vista identificar a relação entre as experiências vividas no espaço acadêmico e sua atuação no mercado profissional. Além disso, tais estudos podem fornecer informações sobre tendências de mercado, desenvolvimento de tecnologia e métodos e processos de trabalho, possibilitando às instituições de ensino redefinir seus currículos para melhor qualificar os profissionais e contribuir para o desenvolvimento das sociedades (COSTA, 1998).

Especialmente a partir dos anos 2000, possivelmente em resposta à já citada emergente preocupação com a qualidade dos cursos, observa-se a realização de estudos sobre egressos (alunos que concluíram o curso e colaram grau) na área de turismo em âmbito acadêmico. Esses estudos abordam egressos em diferentes cursos superiores da área, como Tecnologia em Eventos (CARVALHO, REJOWSKI, 2012) e Tecnologia em Hotelaria (SILVA, 2007). Citase também o trabalho de Araujo (2010), que aborda egressos de cursos variados (turismo, hotelaria, marketing, gastronomia, nutrição, secretariado, e serviço social) empregados em hotéis da cidade de São Paulo.

No que tange a estudos voltados especificamente a egressos de cursos superiores de Turismo, localizaram-se sete publicações: três trabalhos apresentados em eventos, um na área de Educação e dois de Turismo; dois artigos de periódicos científicos, um da área de Turismo outro de Ciências Sociais Aplicadas; uma dissertação de mestrado em Educação, e uma monografia de conclusão de curso em Turismo.

Todos eles aplicaram questionários com bacharéis em Turismo, e a maioria abordou egressos de cursos específicos: da Faculdade Estácio de Sá de Ourinhos, SP (ROSINI, FERREYROS, 2006); da Universidade Federal de São Carlos - UFSCAR, campus Sorocaba (ARAUJO, STIGLIANO, 2010); da Universidade Federal de Minas Gerais - UFMG (SOUZA, GOMES, 2010); da Universidade do Oeste Paulista - Unoeste, Presidente Prudente, SP 
(NASCIMENTO FILHO, 2011) e da Universidade Federal Fluminense - UFF, campus Niterói, RJ (PACHECO, 2011). Freitas et al. (2004) abordaram o bacharelado em Turismo e Hotelaria da Univali, e Medaglia e Silveira (2010) enfocaram bacharéis em Turismo formados em onze instituições de Curitiba, PR. O quadro 1 destaca os objetivos, os respondentes e os principais resultados de cada estudo.

De modo geral, nota-se nesses estudos uma grande preocupação com a inserção dos profissionais no mercado de trabalho, procurando compreender em que áreas atuam, como desenvolveram suas carreiras desde a época de graduandos e de que forma o curso contribuiu para este processo. Além disso, alguns estudos procuram identificar também a satisfação dos egressos com a graduação e como esta contribuiu para sua inserção profissional. Os resultados variam muito em cada estudo, o que provavelmente pode ser explicado pelas diferenças no contexto socioeconômico de cada um. Entretanto, em mais de um deles, notam-se o agenciamento e a hotelaria como áreas que mais empregam, a baixa remuneração do setor e o descompasso entre a academia e o mercado de trabalho.

Deve-se destacar que três dos estudos identificados (MEDAGLIA, SILVEIRA, 2010; NASCIMENTO FILHO, 2011; ROSINI, FERREYROS, 2006) relatam nos aspectos metodológicos dificuldades para localizar e contatar os egressos. Além disso, mesmo em estudos em que tal dificuldade não foi citada, nota-se o baixo retorno de questionários em relação ao universo da pesquisa. Tais dados, somados à escassez de estudos sobre o tema, sugerem que, a despeito de seus evidentes benefícios, o acompanhamento de egressos ainda não é atividade consolidada nos cursos superiores de Turismo, especialmente nos de nível tecnológico, em que nenhum trabalho foi localizado.

Quadro 1: Estudos sobre egressos de cursos superiores de Turismo

\begin{tabular}{|c|c|c|c|}
\hline Estudo & Objetivos & Respondentes & Principais resultados \\
\hline $\begin{array}{l}\text { Freitas et al. } \\
(2004)\end{array}$ & $\begin{array}{l}\text { Avaliar a satisfação dos } \\
\text { egressos na busca pelo } \\
\text { mercado de trabalho }\end{array}$ & $\begin{array}{l}73 \text { egressos de um total de } \\
160 \text { formados de } 2001 \mathrm{e} \\
2002 \text { do Bacharelado em } \\
\text { Turismo e Hotelaria da } \\
\text { Univali, SC. }\end{array}$ & $\begin{array}{l}\text { - Alta satisfação com o curso. } \\
\text { - Hotelaria é a principal área de } \\
\text { atuação. }\end{array}$ \\
\hline $\begin{array}{l}\text { Rosini e } \\
\text { Ferreyros } \\
(2006)\end{array}$ & $\begin{array}{l}\text { Evidenciar as áreas de } \\
\text { atuação, ramo de maior } \\
\text { empregabilidade e } \\
\text { importância destes para o } \\
\text { mercado de trabalho }\end{array}$ & $\begin{array}{l}44 \text { egressos de um total de } \\
50 \text { formados da } 1^{\mathrm{a}} \text { e da } 2^{\mathrm{a}} \\
\text { turmas da Faeso, } \mathrm{SP} .\end{array}$ & $\begin{array}{l}\text { - A maioria não atua na área. Dos que } \\
\text { atuam, destaca-se o setor hoteleiro. Há } \\
\text { no mercado um desconhecimento } \\
\text { sobre a capacidade intelectual e } \\
\text { técnica dos formados em Turismo. }\end{array}$ \\
\hline
\end{tabular}




\begin{tabular}{|c|c|c|c|}
\hline $\begin{array}{l}\text { Araujo e } \\
\text { Stigliano } \\
(2010)\end{array}$ & $\begin{array}{l}\text { Identificar o perfil do egresso } \\
\text { e avaliar como a instituição } \\
\text { contribui para sua formação. }\end{array}$ & $\begin{array}{l}\text { Universo de } 20 \text { egressos } \\
\text { da } 1^{\mathrm{a}} \text { turma da UFSCar, } \\
\text { SP. }\end{array}$ & $\begin{array}{l}\text { - Agenciamento é a principal área de } \\
\text { atuação e estágio. } \\
\text { - O curso foi primeira opção da maioria } \\
\text { dos respondentes. }\end{array}$ \\
\hline $\begin{array}{l}\text { Medaglia e } \\
\text { Silveira } \\
(2010)\end{array}$ & $\begin{array}{l}\text { Identificar a situação } \\
\text { profissional do bacharel em } \\
\text { turismo, com ênfase naqueles } \\
\text { interessados em Planejamento } \\
\text { Turístico. }\end{array}$ & $\begin{array}{l}215 \text { egressos de } 2500 \text { a } \\
5000 \text { bacharéis } \\
\text { (estimativa) formados em } \\
\text { Curitiba, PR. }\end{array}$ & $\begin{array}{l}\text { - Quando recém-formados, a maioria } \\
\text { trabalhava na área de Turismo. } \\
\text { - Má remuneração no mercado. } \\
\text { - Poucos respondentes atuaram em } \\
\text { planejamento turístico. }\end{array}$ \\
\hline $\begin{array}{l}\text { Souza e } \\
\text { Gomes } \\
(2010)\end{array}$ & $\begin{array}{l}\text { Analisar a inserção } \\
\text { profissional dos egressos, } \\
\text { conhecendo os campos de } \\
\text { atuação e as condições de } \\
\text { trabalho. }\end{array}$ & $\begin{array}{l}40 \text { egressos de } 77 \\
\text { formados de } 2005 \text { a } 2007 \\
\text { na UFMG, MG. }\end{array}$ & $\begin{array}{l}\text { - Um pouco menos da metade dos } \\
\text { respondentes atuava na área, com } \\
\text { destaque para agenciamento. } \\
\text { - Baixa remuneração. } \\
\text { - Alta satisfação com as atividades } \\
\text { desempenhadas. }\end{array}$ \\
\hline $\begin{array}{l}\text { Nascimento } \\
\text { Filho (2011) }\end{array}$ & $\begin{array}{l}\text { Analisar a percepção dos } \\
\text { egressos a cerca do papel do } \\
\text { curso em sua formação } \\
\text { profissional e conhecer suas } \\
\text { trajetória e expectativas } \\
\text { profissionais. }\end{array}$ & $\begin{array}{l}48 \text { egressos de } 129 \\
\text { formados na Unoeste, SP } \\
\text { até o momento da } \\
\text { pesquisa. }\end{array}$ & $\begin{array}{l}\text { - Na época da pesquisa, apenas metade } \\
\text { atuava na área. Poucos alunos } \\
\text { plenamente satisfeitos com o curso. } \\
\text { Principal sugestão para melhoria do } \\
\text { curso é a inserção de atividades } \\
\text { práticas. }\end{array}$ \\
\hline $\begin{array}{l}\text { Pacheco } \\
(2011)\end{array}$ & $\begin{array}{l}\text { Analisar a satisfação dos } \\
\text { egressos com o curso, } \\
\text { avaliando a contribuição do } \\
\text { mesmo para sua formação, } \\
\text { enriquecimento pessoal e } \\
\text { inserção profissional. }\end{array}$ & $\begin{array}{l}1^{\text {a }} \text { etapa: } 40 \text { egressos dos } \\
125 \text { formados até } 2009 ; 2^{a} \\
\text { etapa: } 40 \text { dos formados } \\
\text { dos } 159 \text { formados até } \\
2010, \text { no curso da UFF. }\end{array}$ & $\begin{array}{l}\text { - Os egressos se mostram satisfeitos } \\
\text { com os professores, mas insatisfeitos } \\
\text { com a formação específica para o } \\
\text { mercado de trabalho. }\end{array}$ \\
\hline
\end{tabular}

\section{Resultados}

Entre setembro e outubro de 2013, os 644 egressos dos cursos tecnológicos da área de Turismo do campus São Paulo do IFSP foram convidados a responder um questionário online composto de 25 questões. Foram obtidas 338 respostas, quantidade que representa 52,5\% da população total de ex-alunos que já haviam colado grau até aquele momento. Cabe destacar que a dimensão dessa amostra permite um nível de confiança estatística bastante superior ao dos estudos anteriores disponíveis na literatura.

A maioria dos egressos $(89,3 \%)$ não havia concluído outro curso de graduação antes de estudarem Turismo no IFSP. Por outro lado, cerca de um quarto dos entrevistados $(25,8 \%)$ fez algum tipo de pós-graduação após deixar a instituição. A participação dos pós-graduados é maior entre aqueles que concluíram a graduação há mais tempo, atingindo mais da metade para os formados há cinco anos ou mais. Em média, 8,5\% dos egressos concluem uma pós- 
graduação a cada ano que passa. O percentual de pós-graduados em função do tempo decorrido desde a formatura do aluno é apresentado na

Figura 1.

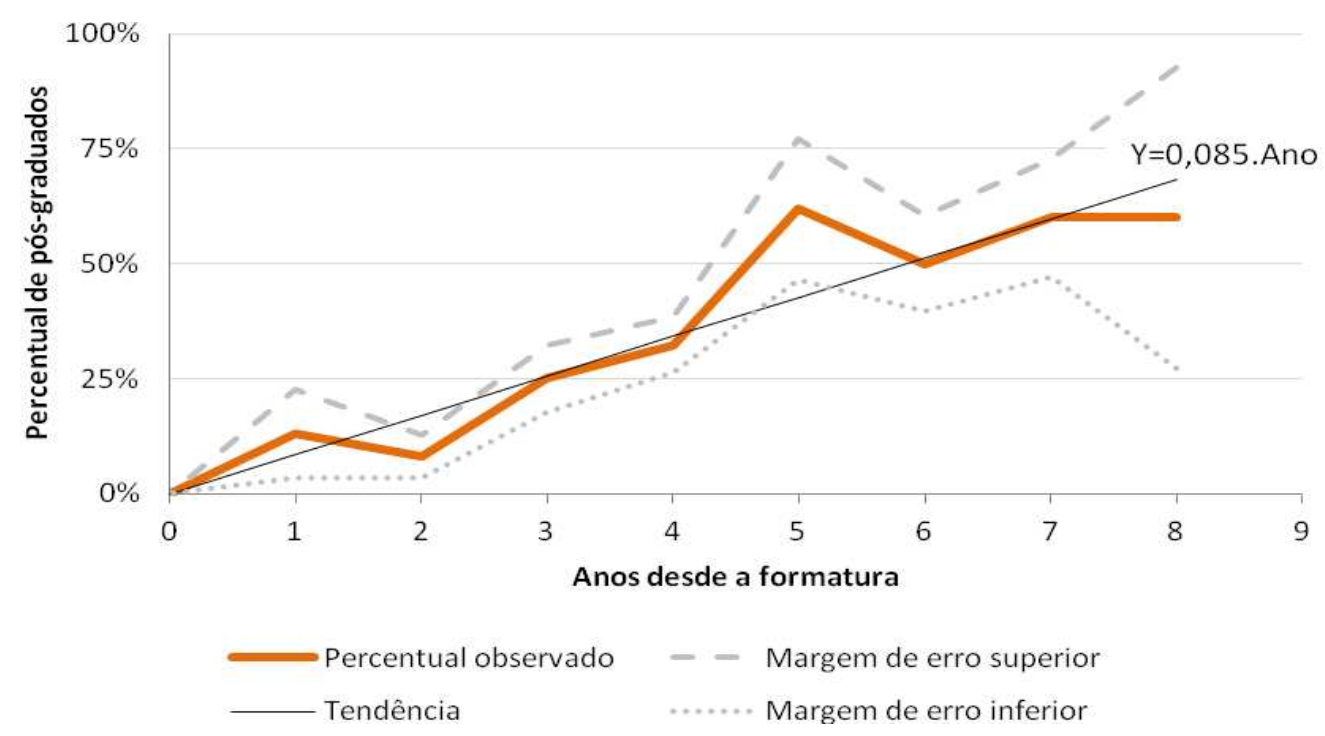

Figura 1: Percentual de pós-graduados por tempo decorrido desde a formatura

Cursos de pós-graduação lato sensu são os mais frequentes, tendo sido cursados por 98,9\% dos pós-graduados. Apenas uma parcela bastante pequena $(3,4 \%)$ dos pós-graduados fez mestrado. A principal área de pós-graduação é a Administração (54,5\%), incluindo suas diversas áreas e variantes. Pedagogia, Ciências Ambientais e Cultura também constituem áreas de pós-graduação relativamente frequentes, conforme apresentado na Figura 2. 


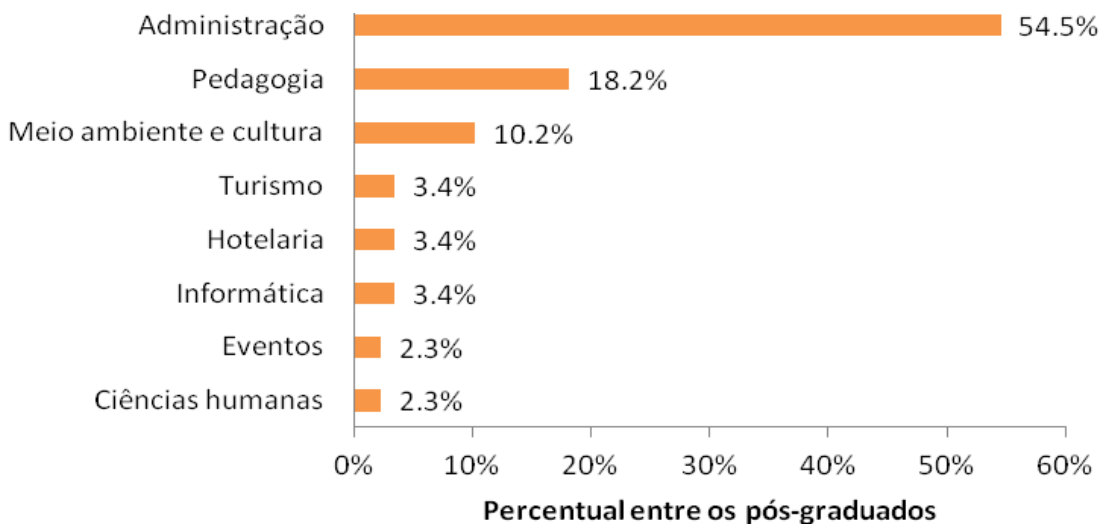

Figura 2: Principais áreas de pós-graduação

Os cursos de Turismo do IFSP-SP revelam relativo sucesso na inserção de seus alunos no mercado de trabalho. Entre os egressos pesquisados, 79,6\% tiveram a experiência de trabalhar na área. Portanto, apenas cerca de um a cada cinco alunos não conseguiu ou não tentou ingressar no mercado profissional de turismo. É interessante notar que a taxa de empregabilidade na área do turismo tem relação com o prazo de término do curso do aluno. Alunos que se formam mais rápido tem maior probabilidade de ingressar no mercado de trabalho de turismo. Contudo, deve-se ressaltar que essa relação apresenta significância estatística moderada $(\mathrm{p}=5,5 \%)$. Os resultados apontam também que a taxa de inserção no mercado tem aumentado ao longo do tempo. Menos de 10\% dos formados a partir de 2012 não ingressaram no mercado de trabalho do turismo, conforme apresentado na Figura 3.

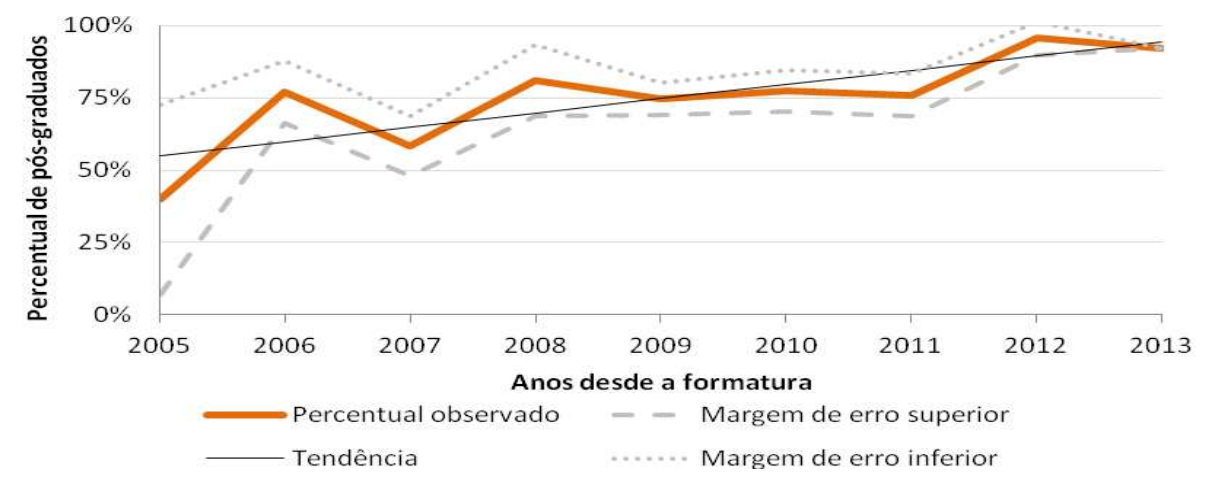

Figura 3: Percentual de alunos que ingressaram no mercado de trabalho de turismo por ano de formatura

A procura ativa por um emprego é a forma mais comum de ingresso na área $(42,6 \%)$. Contatos profissionais e pessoais, a comunicação interna do IFSP-SP e anúncios na mídia 
comum também são meios frequentes para conseguir uma oportunidade no turismo, conforme apresentado na

Figura 4.

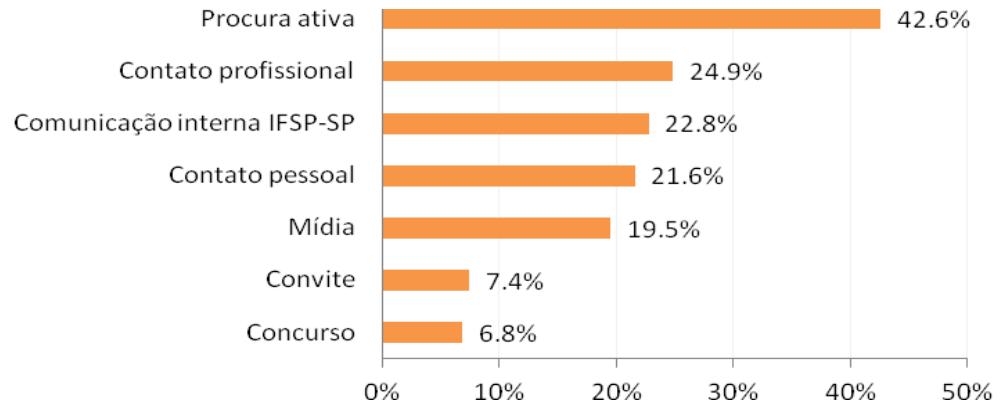

Figura 4: Formas mais frequentes de obtenção de uma oportunidade profissional no turismo

O principal motivo para nunca ter trabalhado no turismo é o fato de estar estabelecido profissionalmente em outra área. Outros fatores importantes são a baixa remuneração e a pequena perspectiva de ascensão profissional. Mais da metade dos entrevistados (51\%) indicou que a dificuldade de conseguir emprego não teve nenhuma importância para não ter ingressado no turismo. Apenas 3\% dos egressos apontaram que não ingressaram na área por não gostar do trabalho, conforme apresentado na Tabela 3.

Tabela 3: Motivos para não ter ingressado na área profissional do turismo

\begin{tabular}{lcccc}
\hline Motivo & $\begin{array}{c}\text { Grande } \\
\text { importância }\end{array}$ & $\begin{array}{c}\text { Média } \\
\text { importância }\end{array}$ & $\begin{array}{c}\text { Nenhuma } \\
\text { importância }\end{array}$ & Total \\
\hline Não gosta do trabalho & $3 \%$ & $18 \%$ & $79 \%$ & $100 \%$ \\
Baixa remuneração & $44 \%$ & $35 \%$ & $21 \%$ & $100 \%$ \\
Baixa perspectiva de ascensão & $29 \%$ & $44 \%$ & $27 \%$ & $100 \%$ \\
Estabelecido em outra área & $61 \%$ & $28 \%$ & $11 \%$ & $100 \%$ \\
Dificuldade de conseguir emprego & $27 \%$ & $22 \%$ & $51 \%$ & $100 \%$ \\
\hline
\end{tabular}

Conforme apresentado na Figura 5, a principal atividade específica da atuação profissional no turismo é o agenciamento de viagens, atividade na qual 48,8\% dos egressos atuaram. Cerca de um terço dos ex-alunos tiveram experiências profissionais na atividade de eventos $(30,8 \%)$ e pouco mais de um quinto $(22,5 \%)$ na hotelaria. Companhias aéreas, guiamento, lazer e recreação também constituem atividades relativamente frequentes. Outras atividades com 
menor incidência incluem serviços de alimentação, locação de veículos, educação, gestão pública, pesquisa, museus e cruzeiros.

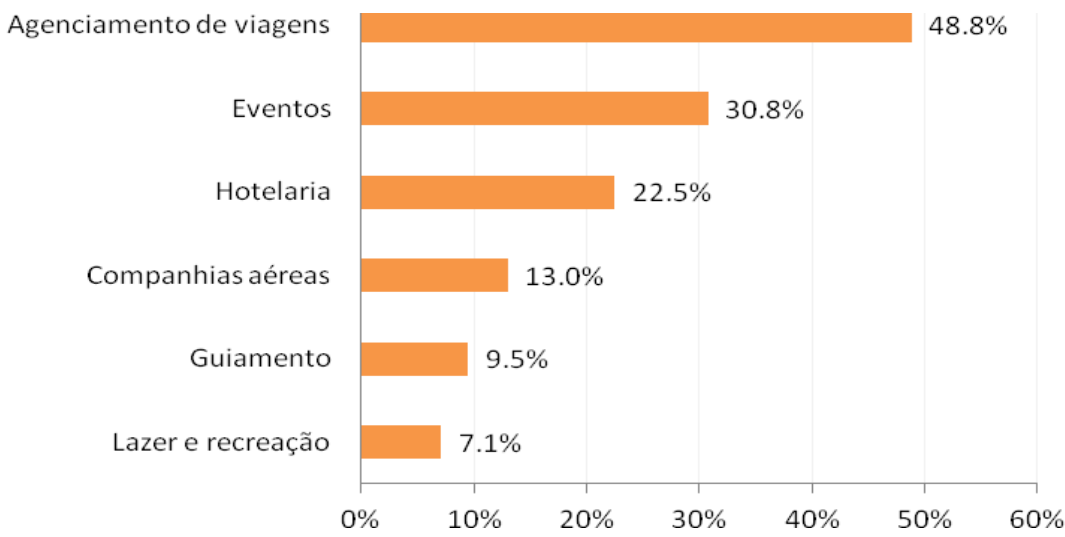

Figura 5: Principais atividades específicas de atuação profissional no turismo

Posições de atendimento ao público são as mais frequentes $(43,1 \%)$ dentre as ocupações atuais dos egressos que atuam no setor de turismo. Outras posições relevantes são as técnicas $(28,5 \%)$ e administrativas (18,2\%). Contudo, uma parcela não desprezível $(10,2 \%)$ dos egressos ocupa atualmente posições de gerência ou direção.

A maior parte dos egressos que trabalham atualmente no turismo está na condição de empregado (76,3\%). Cargos públicos ligados ao turismo são ocupados por $10,1 \%$ dos egressos, enquanto 7,9\% trabalham como autônomos. A participação dos empresários entre os egressos que atuam no turismo é de 5,8\%. A maioria dos ex-alunos $(62,5 \%)$ ganha mais de um até cinco salários mínimos. Cerca de $28 \%$ ganham mais de cinco até dez salários mínimos, conforme apresentado na Figura 6. O patamar salarial dos egressos não está associado ao prazo de término do curso do aluno, de forma que os alunos que demoram mais para se formar não têm remuneração diferente daqueles que se formam em menos tempo. Por outro lado, a remuneração dos egressos varia substancialmente em função do curso de pósgraduação. Enquanto $74,5 \%$ dos ex-alunos sem pós-graduação ganham menos de cinco salários mínimos, apenas 32,9\% dos pós-graduados se encontram nessa faixa de remuneração. Além disso, todos os egressos que ganham mais de quinze salários mínimos têm pósgraduação. 


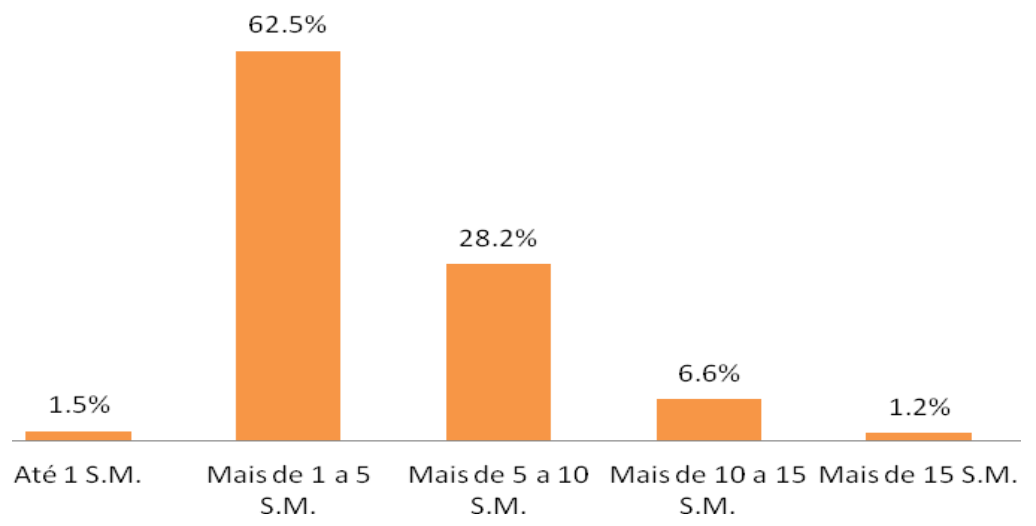

Figura 6: Distribuição dos egressos por remuneração

A satisfação dos egressos que atuam no turismo com relação a diferentes aspectos de seus trabalhos foi mensurada em uma escala de cinco pontos que vai de totalmente insatisfeito a totalmente satisfeito. Os resultados apontam que os colegas e as atividades em si desenvolvidas no trabalho são os aspectos mais positivamente avaliados, sendo que $76 \%$ e 73\% dos egressos se consideram total ou parcialmente satisfeitos com relação a eles. Por outro lado, as perspectivas de carreira e as políticas da empresa são os aspectos em relação aos quais os ex-alunos estão menos satisfeitos. Clientes, remuneração e chefia são elementos que despertam satisfação mediana. De maneira geral, $70 \%$ dos entrevistados indicaram estar satisfeitos com seus trabalhos na área do turismo, enquanto apenas $15 \%$ indicaram estar insatisfeitos. Os resultados detalhados dessa questão são apresentados na

\section{Tabela 4.}

A avaliação geral dos cursos da área de turismo do IFSP-SP é positiva. O grau de satisfação geral do egresso com o curso foi mensurado em uma escala de 1 a 5 ancorada nos conceitos totalmente insatisfeito e totalmente satisfeito. A maioria dos entrevistados $(70,8 \%)$ apontou estar satisfeita com o curso, enquanto cerca de um quarto $(23,2 \%)$ indicou ter uma posição neutra, e uma pequena minoria $(6 \%)$ demonstrou insatisfação, conforme apresentado na Figura 7. Cerca de quatro a cada cinco egressos $(80,2 \%)$ afirmou que indicaria o curso a um amigo. A resposta 'talvez' para a possibilidade de indicação do curso foi selecionada por $18,0 \%$ dos entrevistados. Apenas 1,8\% dos egressos afirmaram que não indicariam o curso para um amigo. 
Tabela 4: Nível de satisfação dos egressos em relação a diferentes aspectos do atual trabalho na área do turismo

\begin{tabular}{lcccccc}
\hline Aspecto & $\begin{array}{c}\text { Totalmente } \\
\text { satisfeito }\end{array}$ & $\begin{array}{c}\text { Parcialmente } \\
\text { satisfeito }\end{array}$ & Neutro & $\begin{array}{c}\text { Parcialmente } \\
\text { insatisfeito }\end{array}$ & $\begin{array}{c}\text { Totalmente } \\
\text { insatisfeito }\end{array}$ & \begin{tabular}{c} 
Total \\
\hline Remuneração
\end{tabular} \\
Atividades desenvolvidas & $24 \%$ & $49 \%$ & $12 \%$ & $21 \%$ & $9 \%$ & $100 \%$ \\
Chefia & $20 \%$ & $49 \%$ & $13 \%$ & $12 \%$ & $1 \%$ & $100 \%$ \\
Colegas de trabalho & $36 \%$ & $36 \%$ & $22 \%$ & $14 \%$ & $8 \%$ & $100 \%$ \\
Clientes & $22 \%$ & $40 \%$ & $16 \%$ & $4 \%$ & $3 \%$ & $100 \%$ \\
Perspectivas de carreira & $16 \%$ & $32 \%$ & $27 \%$ & $7 \%$ & $2 \%$ & $100 \%$ \\
Políticas da empresa & $15 \%$ & $33 \%$ & $21 \%$ & $21 \%$ & $14 \%$ & $100 \%$ \\
Geral & $14 \%$ & $56 \%$ & $15 \%$ & $12 \%$ & $3 \%$ & $100 \%$ \\
\hline
\end{tabular}

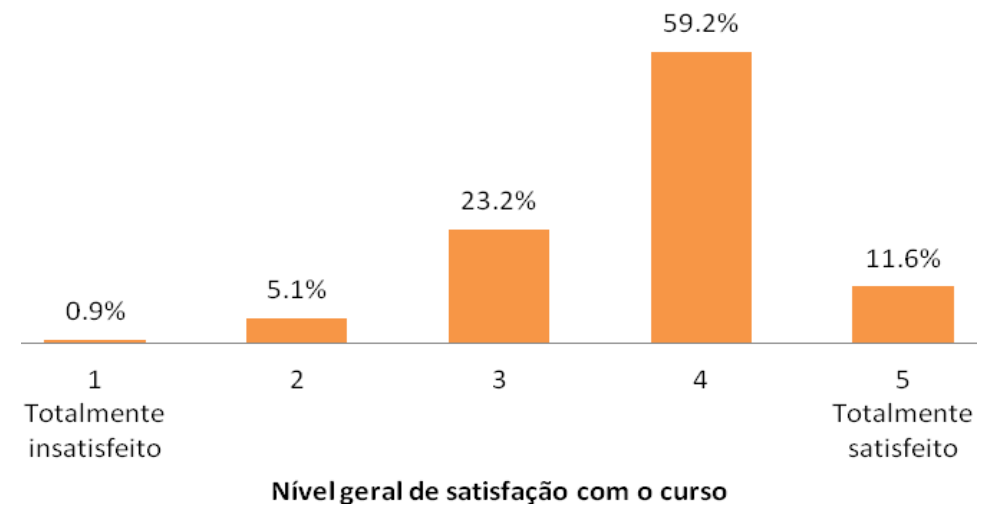

Figura 7: Nível geral de satisfação com o curso

Por fim, foram estudados os determinantes da satisfação dos egressos com o curso. O nível geral de satisfação não apresenta correlação com o ingresso no mercado de trabalho do turismo, o prazo de conclusão do curso, o ano de ingresso, cursos de graduação anteriores ou cursos de pós-graduação. Por outro lado, a satisfação geral com o curso pode ser explicada pela satisfação com alguns aspectos particulares do curso, tais como professores, conhecimentos adquiridos, disciplinas, ambiente social e instituição. Dentre esses aspectos, a satisfação com professores é que apresenta maior efeito sobre a satisfação geral com o curso. Conhecimentos adquiridos e disciplinas têm efeito intermediário, mas apresentam significância estatística apenas moderada. $\mathrm{O}$ ambiente social e a instituição apresentam efeitos comparativamente menores, ainda que significantes. Os efeitos da satisfação com cada aspecto específico sobre a satisfação geral com o curso são apresentados na Tabela 5. 
Tabela 5: Resultados do modelo de explicação da satisfação geral com o curso ${ }^{7}$

\begin{tabular}{ccc} 
Variável & Coeficiente & p-valor \\
\hline Professores & 0,180 & 0,01 \\
Conhecimentos adquiridos & 0,147 & 0,05 \\
Disciplinas & 0,131 & 0,06 \\
Instituição & 0,126 & 0,01 \\
Ambiente social & 0,120 & 0,01 \\
Constante & 1,67 & 0,00 \\
\hline
\end{tabular}

\section{Considerações Finais}

O presente estudo contribui para a ampliação do conhecimento a respeito dos efeitos dos cursos superiores de tecnologia em Gestão de Turismo. Os resultados da pesquisa de egressos apresentados oferecem informações relevantes para a análise das perspectivas de empregabilidade dos alunos atuais e futuros, permitindo um melhor planejamento e orientação desses cursos. Este estudo se destaca dos anteriores em razão das dimensões de sua amostra, oferecendo grande nível de confiabilidade estatística. Deve-se destacar a relevância do curso enfocado, já que o curso de tecnologia em Turismo do IFSP é um dos mais antigos e mais bem avaliados do país, além de ser o maior oferecido por instituições públicas do Estado de São Paulo.

Os resultados apresentados destacam a grande incidência e a importância dos estudos de pósgraduação para a empregabilidade do egresso. Contudo, mesmo sem se pós-graduar, os alunos do IFSP têm alcançado altos níveis de empregabilidade, já que praticamente apenas um a cada cinco não teve nenhuma experiência profissional na área. Dentre os principais motivos para não ter ingressado na área profissional do turismo estão o fato do aluno já estar estabelecido em outra área e a baixa remuneração. Nota-se também que a taxa de empregabilidade dos egressos tem aumentado ao longo do tempo, fato que pode estar associado não apenas ao aprimoramento do curso, mas também ao processo de formação de reconhecimento do curso pelas empresas do mercado. A principal atividade empregadora dos egressos é o agenciamento de viagens. Contudo, não se pode desprezar a relevância das atuações nas áreas

\footnotetext{
${ }^{7} \mathrm{O}$ modelo de explicação consiste em uma regressão linear na qual a satisfação geral com o curso é tida como variável dependente e os níveis de satisfação com os aspectos específicos são utilizados como variáveis explicativas. Todas as variáveis foram mensuradas em uma escala de 1 a 5 , onde 5 indica o maior nível de satisfação.
} 
de eventos, hotelaria e companhias aéreas. Os egressos que atuam profissionalmente na área de turismo se mostram relativamente satisfeitos, sendo que apenas $15 \%$ têm opiniões negativas sobre seus trabalhos atuais.

Em relação ao curso do IFSP, os egressos também apresentam opiniões positivas. Apenas $6 \%$ declararam estar insatisfeitos, ao passo que cerca de $80 \%$ afirmaram que recomendariam o curso a amigos. Alunos mais satisfeitos com o curso são aqueles que demonstraram maior satisfação com os professores, conhecimentos adquiridos, disciplinas, ambiente social e com a instituição. Em particular, nota-se que a satisfação com os professores pode ser considerada o principal elemento determinante da satisfação geral com o curso.

Ao mesmo tempo em que o presente estudo pode ser feito pelos outros cursos de tecnologia em Gestão de Turismo existentes no país para que se conheça a realidade mais ampla desse tipo de graduação (a tecnológica) e de seus egressos, deve-se ressaltar que os resultados desses outros estudos podem ser muito diferentes dos aqui apresentados, tendo em vista as diversas realidades socioeconômicas do território brasileiro e, sobretudo, as diferentes características do mercado turístico da localidade, questões que certamente interferem na empregabilidade e nas atividades que os egressos acabam exercendo após o término do curso.

\section{Referências}

AIREY, D. Crescimento e desenvolvimento. In: AIREY, D.; TRIBE, J. (Org.). Educação internacional em turismo. São Paulo: SENAC, 2008a.

AIREY, D. Tourism Education: life begins at 40. Teoros, v. 27, n. 2, p. 27-32, 2008 b.

ANSARAH, M. D. R. Formação e capacitação do profissional em turismo e hotelaria. São Paulo: Aleph, 2002.

ANSARAH, M. D. R.; REJOWSKI, M. Panorama de ensino em turismo no Brasil - graduação e pósgraduação. Turismo em Análise, v. 7, n. 1, p. 36-61, 1996.

ARAUJO, C. R. M. D.; STIGLIANO, B. V. O Perfil do Bacharel em Turismo: a primeira turma de egressos do Curso de Bacharel em Turismo da Universidade Federal de São Carlos. In: $6^{\circ}$ Seminário em Pesquisa do Mercosul - Semintur 2010, Caxias do Sul (RS). Universidade de Caxias do Sul.

ARAUJO, U. A. M. D. Os Egressos dos Cursos Superiores em Hotelaria que atuam nas Organizações Hoteleiras na Grande São Paulo (Doutorado) - Instituto Superior de Economia e Gestão, Universidade Técnica de Lisboa, Lisboa, 2010.

BARRETTO, M.; TAMANINI, E.; SILVA, M. I. P. D. Discutindo o ensino universitário de turismo. Campinas (SP): Papirus, 2004.

BRASIL. MINISTÉRIO DA EDUCAÇÃO. Centenário da Rede Federal de Educação Profissional e Tecnológica. $2009 . \quad$ Brasília, Disponível em: 
<http://www.educacao.gov.br/setec/arquivos/centenario/historico_educacao_profissional.pdf $>$. Acesso em: 15 Jun. 2014.

BRASIL. MINISTÉRIO DA EDUCAÇÃO. Catálogo Nacional de Cursos Superiores de Tecnologia. Brasília: 2010.

BRASIL. MINISTÉRIO DA EDUCAÇÃO. E-MEC. Disponível em: <Erro! A referência de hiperlink não é válida.. Acesso em: 24 Mai. 2014.

CARVALHO, M. A. Os números do ensino superior em turismo e hospitalidade no Brasil - 2001 a 2006. In: Seminário da Associação Nacional de Pesquisa e Pós-Graduação em Turismo 2008, Belo Horizonte.

CARVALHO, W. L. D.; REJOWSKI, M. Tecnologia em eventos da Faculdade Hotec, São Paulo: proposta de formação versus atuação profissional de egressos. Revista Hospitalidade, v. 9, n. 1, p. 82104, 2012.

COOPER, C.; SHEPERD, R.; WESTLAKE, J. Educando educadores em turismo: manual de educação em turismo e hospitalidade. São Paulo: Roca, 2001.

COSTA, S. D. A Educação Tecnológica e a Interação Escola-Empresa (Mestrado) - Educação, Universidade Federal de Santa Maria, Santa Maria (RS), 1998.

DENCKER, A. D. F. M. Estado e educação no Brasil: o caso do ensino de Turismo. In: Congresso Brasileiro de Ciências da Comunicação 2006, Brasília.

FREITAS, C. M. et al. A Inserção no Mercado de Trabalho dos Egressos do Curso de Turismo e Hotelaria da Universidade do Vale do Itajaí. In: IV Colóquio Internacional sobre Gestão Universitária na América do Sul 2004, Florianópolis. Universidade Federal de Santa Catarina.

FUVEST. Relação Candidato/Vaga por Carreira. Disponível em: <http://www.fuvest.br/vest1997/estat/estat.stm>. Acesso em: Jun. 2014.

INSTITUTO NACIONAL DE ESTUDOS E PESQUISAS EDUCACIONAIS ANÍSIO TEIXEIRA. Resultados do Enade 2009. Disponível em: <http://portal.inep.gov.br/enade/resultados〉. Acesso em: 15 Jun. 2014.

MEDAGLIA, J.; SILVEIRA, C. E. Reflexões sobre a atuação profissional dos turismólogos e o planejamento do turismo: pesquisa com os egressos dos cursos de Turismo de Curitiba, Paraná, Brasil. Turismo e Sociedade, v. 3, n. 2, p. 123-146, 2010.

NASCIMENTO FILHO, F. B. Diaólogos com egressos do curso de Turismo da Unoeste: um percurso de auto-avaliação (Mestrado) - Educação, Universidade do Oeste Paulista, Presidente Prudente (SP), 2011.

PACHECO, A. P. C. Educação superior em Turismo: a visão do egresso da Universidade Federal Fluminense (Graduação) - Turismo, Universidade Federal Fluminense, Niterói, 2011.

REJOWSKI, M. Turismo e pesquisa científica: pensamento internacional versus realidade brasileira. Campinas (SP): Papirus, 1996.

ROSINI, F.; FERREYROS, A. R. S. Situação profissional dos egressos da primeira e segunda turma do curso de Turismo da faculdade Estácio de Sá de Ourinhos - SP. Horus Jr. - Revista de Humanidades e Ciências Sociais Aplicadas, v. 1, n. 1, 2006.

SILVA, S. M. C. Formação de tecnólogos em hotelaria: um estudo com egressos (Mestrado) Educação, Universidade Metodista de Piracicaba, Piracicaba (SP), 2007.

SOUZA, T. R. D.; GOMES, C. L. A Inserção Profissional dos Bacharéis em Turismo formados Pela UFMG no Período de 2005 a 2007. In: 6 Seminário em Pesquisa do Mercosul - Semintur 2010, Caxias do Sul (RS). Universidade de Caxias do Sul. 
STERGIOUS, D. Ensino. In: AIREY, D.; TRIBE, J. (Org.). Educação internacional em turismo. São Paulo: SENAC, 2008.

TEIXEIRA, S. H. A. Cursos Superiores de Turismo: uma abordagem histórica (1970/1979). In: Congresso Brasileiro de História da Educação 2006, Goiânia. Pontifícia Universidade Católica de Goiás.

WANG, J.; AYRES, H.; HUYTON, J. Is tourism education meeting the needs of the tourism industry? An Australian case study. Journal of Hospitality and Tourism Education, v. 22, n. 1, p. 8-14, 2012.

Recebido em: 10/03/2015

Aprovado em: 21/07/2015 